\title{
Sir William Osler and gastroenterology
}

\author{
Hugh Chaun MA BM BCh FRCP FRCP(Edin) FRCPC FACG AGAF
}

\author{
"One finger in the throat and one in the rectum makes a \\ good diagnostician." \\ - William Osler
}

Cir William Osler (1848-1919) was born in the tiny hamlet $\checkmark$ of Bond Head, Ontario. Osler's father, Featherstone Osler, was a Cornishman. When he retired after a brief career in the Royal Navy, he became an Anglican clergyman. In 1837, he emigrated to Canada with his wife, formerly Ellen Picton, having been appointed to a posting with the Anglican church in the isolated community of Bond Head. William (Willie) was the couple's eighth child. When he was eight-years-old, his family moved to Dundas, Ontario. He was sent to boarding school in Barrie, Ontario, and, subsequently, to a new school in Weston, later renamed 'Trinity College School for Boys', nearer to the family home. His tendency to indulge in practical jokes at school became a lifelong penchant, although at more socially acceptable moments as an adult. He developed a curiosity with natural phenomena (1).

The young Osler shifted from his earlier interest in divinity to medicine. As a medical student at the University of Toronto (Toronto, Ontario), he spent many hours in the dissecting rooms of the anatomy department. By now, Osler was entrenched in the methods he would follow lifelong, carefully observing and recording natural phenomena and drawing conclusions from them. He transferred to McGill University (Montreal, Quebec) before he completed his second year in Toronto because the clinical opportunities in Montreal hospitals were reputed to be superior. He was 23 years of age when he graduated. He subsequently embarked on a two-year program to study abroad, with a provision of $\$ 1000$ from his older brother Edmund, a lawyer, enabling him to be financially secured while he was away. Osler spent 17 months in London, United Kingdom, working in histology and physiology, and 'walked the hospital wards' at St Thomas's and University College, commenting on 'the admirable English system'. After London, he went to Berlin, Germany, where he was extremely impressed by Virchow's meticulous postmortems, then to Vienna, Austria, where he attended the lectures of pathologist Carl Rokitansky. Pathology continued to be Osler's passionate interest (1-3).

\section{OSLER'S MEDICAL CAREER}

Not long after he returned to Canada in 1874, Osler was appointed as a lecturer in physiology and pathology at McGill University, his alma mater. He supplemented his income by caring for patients in the smallpox wards of the Montreal
General Hospital (Montreal). His collection of pathological specimens from the hospital's autopsy room later became the basis of the McGill Pathological Museum (1). He started a journal club. He soon became a prolific author, with many publications. In 1884, Osler accepted an offer to be the chair of clinical medicine at the University of Pennsylvania, (Philadelphia, USA) the second oldest medical school (after Harvard) in the United States (1). At 35 years of age, having spent the earlier years of his career in the pathology laboratory, he was increasingly interested in the study of disease at the bedside. He confined himself to a consultant practice - a rarity at the time. In 1889, Osler left for the newly established teaching hospital at the recently founded Johns Hopkins University in Baltimore (USA). The opening of the medical school there in 1893 was described as the most spectacular innovation in the history of American medical education. Under Osler's influence, the institution flourished and became firmly established as the pinnacle of medical education in America (1). By then, Osler had embarked on his most celebrated book, The Principles and Practice of Medicine. The first edition was published in 1892 and was an immediate bestseller. The seventh was his last single-authored edition. The final edition of the book - the seventeenth - was published in 1968 (4). In 1891, he married Grace Revere in Philadelphia. Osler was 56-years-old in 1904 when he was appointed to the Regius Professorship of Medicine at Oxford University (United Kingdom), founded by King Henry VIII in 1564 (2) (Figure 1). His residence at Oxford, 13 Norham Gardens, named 'Open Arms' (Figures 2 and 3), was an 'open house' to many of his British, Canadian, American and other international colleagues, students and Rhodes scholars.

In King George V's coronation honours list, Osler was awarded a baronet. The Oslers' only child, Edward Revere Osler, born in Baltimore (USA) in 1896, had just begun his university studies at Christ Church, Oxford, when he was recruited to the Royal Field Artillery and subsequently sent to France. In August 1917, he was severely wounded by multiple shrapnel fragments and succumbed to his injuries, leaving Sir William grief stricken (1).

\section{THE GREATEST PHYSICIAN OF THE PAST CENTURY}

Osler's status as Canada's most illustrious physician was commemorated by First Day of Issue - Jour d'Emission - postage stamps bearing his portrait on June 23, 1969. He wrote more than 1500 articles and books. He had a special interest in the natural history of diseases (5). Although he was the most

Division of Gastroenterology, Department of Medicine, University of British Columbia, Vancouver, British Columbia

Correspondence and reprints: Dr Hugh Chaun, 3185 West 45th Avenue, Vancouver, British Columbia V6N 3L9.

Telephone 604-261-8437, fax 604-872-7921, e-mail hchaun@mac.com

Received for publication April 24, 2010. Accepted April 29, 2010 


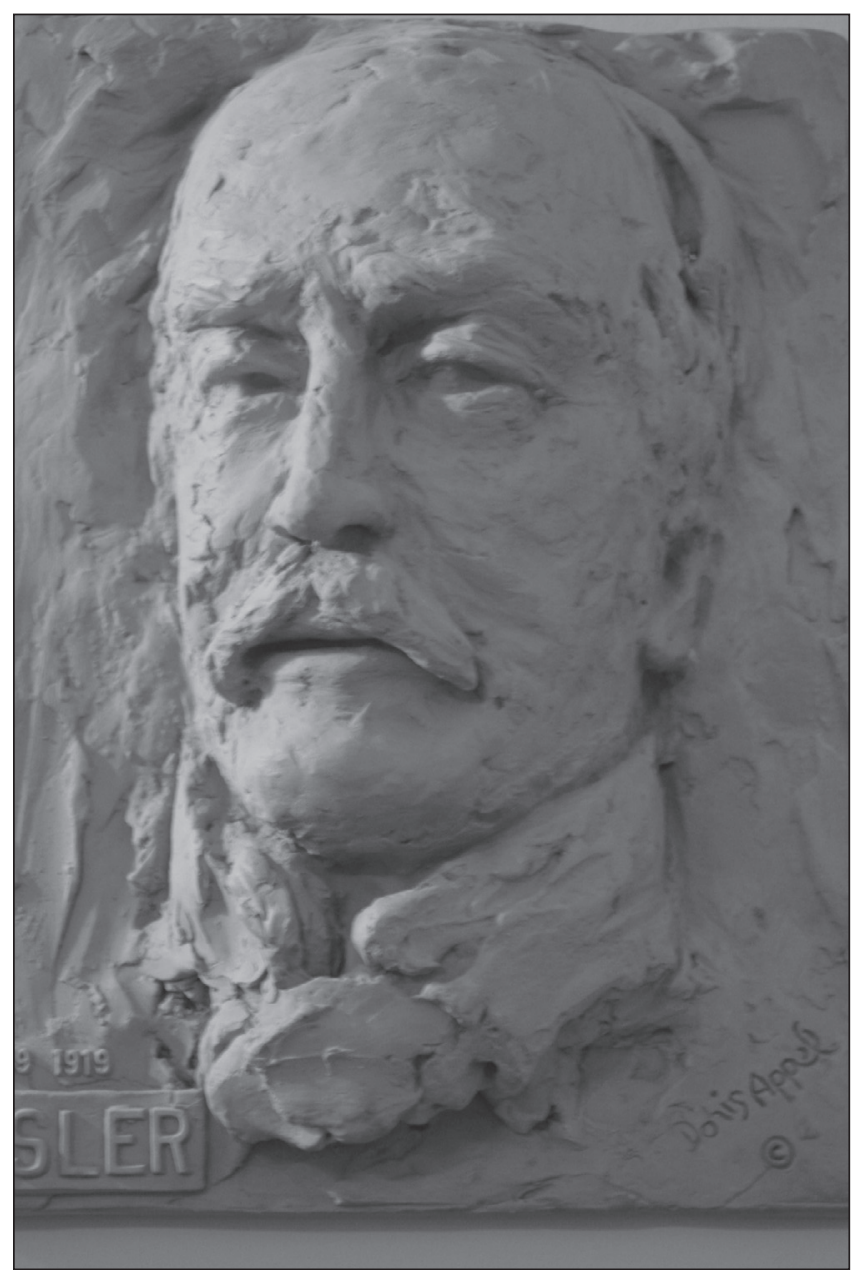

Figure 1) Sculpture of Osler, Osler Library, Oxford, United Kingdom

famous general physician of his era and beyond, it is of interest that many of his writings and publications pertained to a diversity of gastrointestinal disorders, some of which have remained challenging clinical issues of today. By 1897, Osler had personified the internist as the broadly oriented scholarclinician and general medical consultant encompassing all medical interests. He abjured specialization and would never have regarded himself as anything other than a general physician. As for gastroenterologists, there was concern of a 'narrow point of view, and overuse of the stomach tube' (6).

Among the historical heritage of Montreal, one jewel is the Osler Library at McGill University, Canada's national library for the history of medicine (7). Osler had bequeathed his magnificent library of 8000 volumes of medical, scientific and literary works to McGill, transferred to Montreal from Oxford in 1929. By 1991, the library's collection had grown to 40,000 volumes (8).

\section{OSLER AND GASTROENTEROLOGY}

Osler's first contribution to gastroenterology occurred when, as a young medical student in Toronto, he was given a postmortem specimen of a huge aortic aneurysm by the school pathologist to describe and draw. He noted its extrinsic pressure on the esophagus (8). His early interest in pathology is well recognized and, as he became more involved in clinical

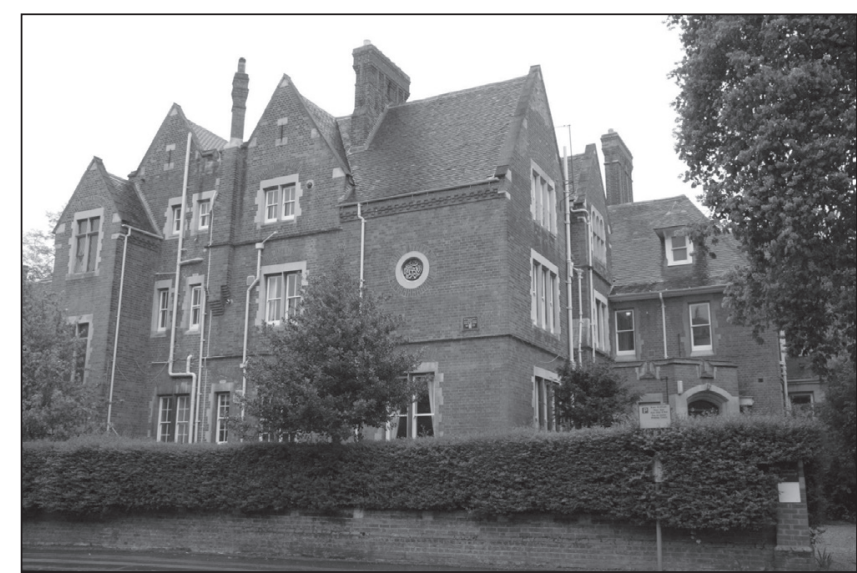

Figure 2) Osler's residence at Oxford: 13 Norham Gardens, named 'Open Arms'

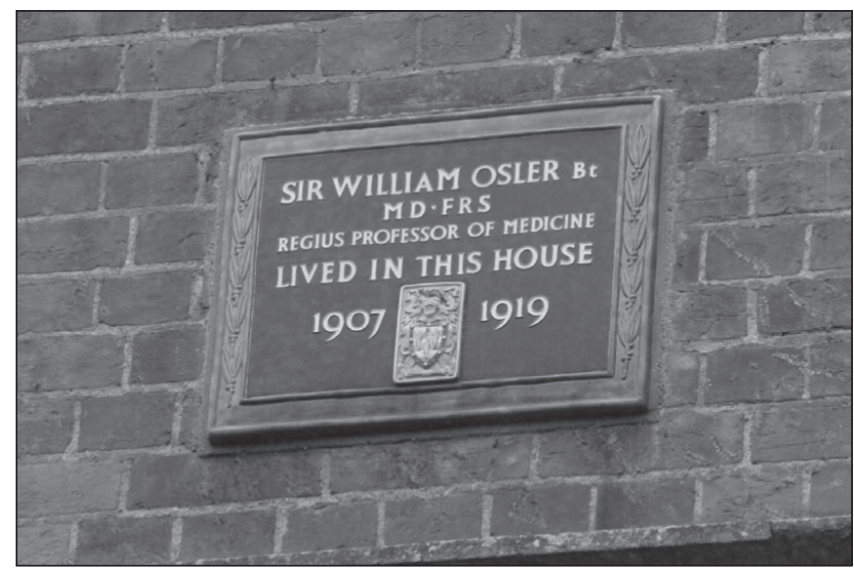

Figure 3) Plaque commemorating Osler's residence at Oxford

work, he continued to be an avid pathologist when he was in Montreal and in Philadelphia. He performed 786 autopsies during his seven years at the Montreal General Hospital, and 162 in less than five years at the Philadelphia General Hospital, reporting his findings in meticulous detail in his own handwriting (8).

\section{OSLER'S BROAD INTERESTS IN CLINICAL MEDICINE ENCOMPASSED MANY DISEASES OF THE DIGESTIVE SYSTEM}

\section{Hepatobiliary diseases}

Osler published articles on 'Liver disease as a basis for some angiomata' and 'The relationship of spider nevi and hepatic cirrhosis', indicating that the most interesting association of the spider nevus is with cirrhosis. He wrote on jaundice, that "jaundice is a disease that your friends diagnose" (9). He had articles on 'Aneurysm of the Hepatic Artery', 'The Liver in Atrophic Cirrhosis', 'Perihepatitis' and 'The Ball Valve Mechanism in Gallstones'. He wrote editorials on a specific cure for gall stones, whether amyloid disease of the liver (or kidneys) was curable, whether cirrhosis was curable, recovery in cirrhosis, cirrhosis in children and one editorial arguing against hepatic puncture then advocated as a diagnostic procedure. He discussed ascites associated with cirrhosis. He prescribed high-carbohydrate and high-protein diets as therapy for cirrhosis (8). 


\section{The stomach}

"The stomach is the hardest worked and most abused organ of the body, more subject also to irritation than any other,..." (9).

"Stomach troubles are often due to omphalism of a high order - self-centered gazing at our navels" (9).

"A greatly distended stomach is an epigastric swill barrel which should be turned up and emptied occasionally" (9).

\section{Dyspepsia and nutrition}

Osler referred to dyspepsia as the 'besetting malady' of the day, and he attributed it to an improper diet, poorly prepared and eaten too hastily (6). He blamed ruined digestion, especially in young girls, to sweets eaten between meals and drinking of items dispensed in chemists' shops such as ice cream sodas. Businessmen having hurried meals at the lunch counter was another frequent cause of maldigestion. Most importantly, he emphasized that "more people are killed by over-eating and drinking than by the sword..." (6). Overeating and obesity have become major maladies in the developed regions of the world today, more than one century after Osler's warning of the consequences of excessive food indulgence.

\section{Peptic ulcers}

Osler described pain as perhaps the most constant and distinctive feature of (peptic) ulcer, varying greatly in character. It might only be a gnawing or burning sensation, particularly experienced in an empty stomach, relieved by eating food. He stated that the more characteristic form occurred in paroxysms of the most intense gastralgia in which the pain, not only experienced in the epigastrium, would radiate to the back and to the sides.

Osler published an editorial in 1887 on the 'Etiology of Gastric Ulcer', advancing Rasmussen's theory of rib edge pressure on the stomach, and the greater frequency of stomach ulcers in females because of corsetting. He also attributed ulcer occurrence to nutritional disturbance in a limited region of the mucosa that resulted in gradual destruction by gastric juice and an excess of hydrochloric acid. He cited occupations in which inward pressure in the rib margin predisposed to ulcer disease. His views on gastric ulcer were also based on postmortem observations. In his day, gastric ulcers were believed to be much more common than duodenal ulcers. Osler stated that $90 \%$ of gastric ulcers occurred in the region of the pylorus, and almost all duodenal ulcers in the first portion of the duodenum. He classified them into the following eight categories: latent, acute perforating, acute hemorrhagic, gastralgic - the dyspeptic form (the most common), chronic hemorrhagic, cachectic, recurrent and stenotic types $(6,8)$.

For the entity that he termed 'simple chronic gastritis', Osler observed that, toward the pylorus, the mucosa was not infrequently irregularly pigmented and presented a rough, wrinkled, mammillated surface (10). In retrospect, it is possible that he may have described changes caused by Helicobacter pylori infection.

He recognized that a large number of ulcers healed completely, but often took months to do so. His treatment included absolute bed rest, a controlled diet of bland, easily digested food given at stated intervals, lavage with mildly alkaline water in selected cases, baking soda, bismuth, nitrate of silver, lavage for vomiting, opium for hemorrhage and, occasionally, transfusion or subcutaneous infusion of saline.
He cited that perforation occurred in $28 \%$ of cases, and hemorrhage in more than $8 \%$. He discussed the merits of stomach lavage, fashionable in the management of dyspepsias in his day. In 1888, he had publications on the sex differences, and the relative frequency and associated disorders of duodenal and gastric ulcers. There was a case report of perforated pyloric ulcer, and another on cancer of the pyloric area of the stomach (8).

\section{Cancer of the stomach}

In the early 1900s, Osler was a co-author in a review of 150 cases of cancer of the stomach published in the Philadelphia Medical Journal. The authors published a monograph on the same topic, based on the clinical and pathological records of the Johns Hopkins Hospital. He also published two articles on gastric cancer in young people. In 1898, Osler's views on cancer of the stomach were that it may rarely develop in a simple ulcer, and that gradual failure of health and death may occur without any suspicion of underlying malignant disease (8).

Diagnosis depended on progressive anemia, weight loss, emaciation, intractable dyspepsia, coffee ground vomitus, absence of free hydrochloric acid and confirmed by a palpable tumour mass. He described gastric lavage in facilitating the palpation of the tumour, and distending the stomach with gas from Seidlitz powder as another diagnostic manoeuvre. Twenty-five years later, in 1916, he mentioned the finding of occult blood in the stool, and ' $\mathrm{x}$-rays are sometimes an aid in diagnosis' (26 years after the discovery of $x$-rays by Roentgen, and approximately 10 years after Cannon's introduction to the use of barium). Osler also advocated the 'safety' of exploratory laparotomy in making the diagnosis. His 'Lectures on the Diagnosis of Abdominal Tumors' were published as a monograph in 1896, with at least two-thirds dealing with large tumours of the stomach. In this publication, he drew attention to the simultaneous occurrence of carcinoma of the ovary and the stomach (an early description of Krukenberg tumour). In 1902, he wrote a paper on the occurrence of ascites in solid abdominal tumours (8). There was one perplexing case described in the monograph of a tumour mass of 10 months' duration in the right iliac fossa which, at laparotomy, was shown to be 'an extensive new growth involving the cecum and extending a short distance into the ileum' (8). This may have been an early description of Crohn's disease.

\section{Bacterial and parasitic diseases}

In 1888, a shipload of workers arrived in Philadelphia from Panama during the initial attempt to build a canal there. Osler was appalled by the sight of their bodies, which had been ravaged by malaria and dysentery (8).

Osler fought to upgrade public health in the management of typhoid fever. He wrote a paper titled 'Perforation and Perforative Peritonitis in Typhoid Fever'. While he was in Montreal, an epidemic of typhus fever emerged and one of his brilliant young house physicians died. He had a similar experience later in Baltimore during a typhoid outbreak. Circa 1890, Osler published papers on amoebic liver abscess, intermittent pyrexia associated with gallstones and multiple cysticerci of the liver. In a case seen in consultation in Baltimore, the puncture of a liver abscess was followed by the discovery of amoebae in the aspirated fluid. In an article in 1902, he wrote that the most frequent form of abscess of the liver seen in Baltimore was that which was secondary to amoebic dysentery. He drew 
attention to the prevalence of echinococcus disease in America, and cited 61 cases from his own autopsy experience (8).

\section{Miscellaneous gastrointestinal disorders}

In 1901, Osler described hereditary hemorrhagic telangiectasia, now referred to as Osler-Weber-Rendu syndrome, in a case report (10). In 1903, he published a paper on 'Congenital Hypertrophic Stenosis of the Pylorus'.

He handwrote a manuscript on 'The Clinical and Pathological Relationships of the Cecum and Appendix' and, in Philadelphia, presented a case of perforation of the appendix with a circumscribed abscess perforating into the bowel. In a presentation of the histories and postmortem findings of 33 cases of appendicitis, Osler described seven anomalous positions of the appendix.

He labelled as remarkable a case involving 53 diverticulae of the jejunum, one of which had perforated causing hemorrhage and death. A rare case he reported concerned the passage of a large segment of gangrenous bowel per rectum, and another of the sloughing of the pancreas 'in toto' into the colon and passed rectally. He drew attention to proliferative peritonitis and recurrent ascites complicating the syndrome of adhesive peritonitis, which Osler described in 1894. In 1912, he published a paper on 'Angina Abdominis', and drew attention to epigastric pain as a possible manifestation of heart disease. His first article on pancreatic disease appeared in 1907 in the British Medical Journal regarding the diagnosis of acute pancreatitis. He later wrote on the interstitial changes in chronic pancreatic disease (8).

\section{GASTROENTEROLOGY PUBLICATIONS}

From 1900 to 1901, Osler wrote the largest number of papers on gastrointestinal subjects - fully $90 \%$ of his publications. During his working career, he published an average of 30 papers per year. Of his final 10 papers, eight were on gastrointestinal topics such

\section{REFERENCES}

1. Grant T. Doctors' Work - The Legacy of Sir William Osler. Firefly Books Ltd, Toronto, 2003.

2. Bliss M. William Osler: A life in medicine. University of Toronto Press, Toronto, 1999.

3. Bliss M. William Osler at 150. Can Med Assoc J 1999;161:831-40.

4. James DG. Osler's two centenary celebrations. R Coll Physicians Lond 1993;27:185-6.

5. Bouchier IAD. William Osler. A Life in Medicine by Michael Bliss. Proc R Coll Physicians Edin 2001;31:90.

6. Kirsner JB. The Development of American Gastroenterology. Raven Press, New York, 1990. as Hirschsprung's disease, alcoholic jaundice, nonleukemic splenic enlargements, visceral syphilis and the story of 'Old Fistulous Alexis' - St Martin and Beaumont's epoch physiological studies. After St Martin's death in St Thomas, Quebec, in 1880 at approximately 86 years of age, his family rejected Osler's request to purchase his stomach 'at a fair price' (6).

\section{A MEDICAL CAREER IN THREE COUNTRIES}

Sir William Osler had distinguished careers in Montreal, Baltimore, Philadelphia and Oxford. At Oxford, he increasingly assumed the role of a medical philosopher. His sense of responsibility to humanity was reflected by many of his sayings:

"Men who have risen to the highest of distinctions in the field of medicine devote their time and energies to the services of the poor ... Great material prosperity has weakened the influence of ideals, and blurred the eternal difference between means and end ... Medicine is the only worldwide profession, following everywhere the same methods, actuated by the same ambitions and pursuing the same ends" (1).

Sir William Osler died at 70 years of age on December 29, 1919, in Oxford (11) of empyema and other infections secondary to influenza.

DISCLAIMER: This article was first presented as an abstract, History of Medicine: Osler and Gastroenterology, at Canadian Digestive Diseases Week, Banff, Alberta, February 16 to 20, 2007 (Can J Gastroenterol 2007;21[Suppl A]:103A).

ACKNOWLEDGEMENT: The author is indebted to Dr William S Haubrich, La Jolla, California, USA, archivist of the Bockus International Society of Gastroenterology, for his advice and encouragement in the preparation of this manuscript.

7. Chaun H. McGill's Osler Library, Osler and Gastroenterology. World Gastroenterol News 2006;11 (Special online only content).

8. Cunha F. Osler as a Gastroenterologist. Times Star Press, Alameda, California, 1948.

9. Silverman ME, Murray TJ, Bryan CS. The Quotable Osler. Am Coll Physicians, Philadelphia, 2003.

10. Osler W. The Principles and Practice of Medicine. D Appleton \& Company, New York, 1892.

11. Associated Press Despatch. Sir William Osler, a Great Canadian, is dead in England. The Globe, Toronto, December 30, 1919. 


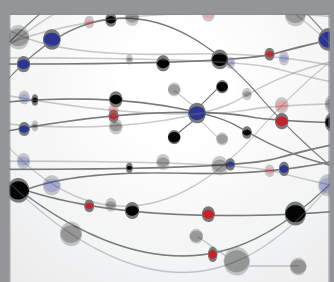

The Scientific World Journal
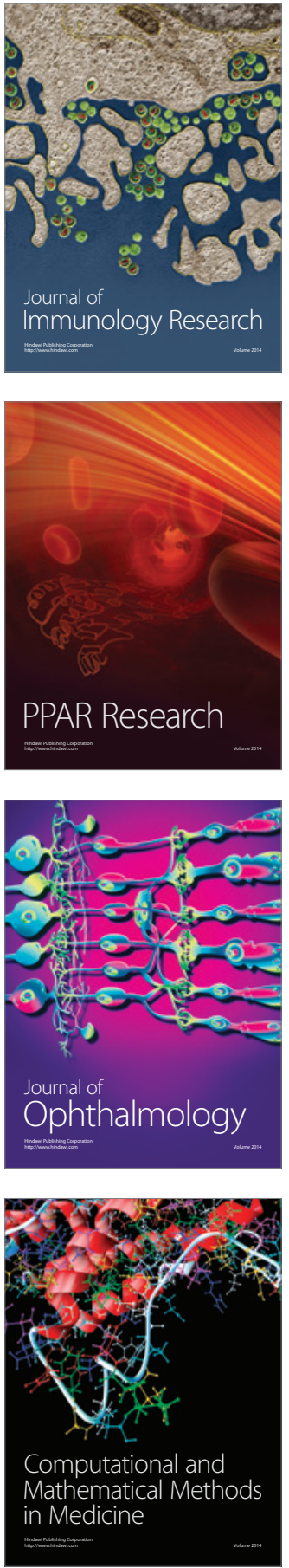

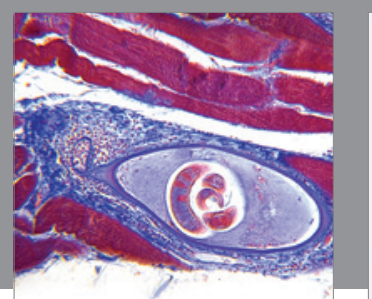

Gastroenterology Research and Practice

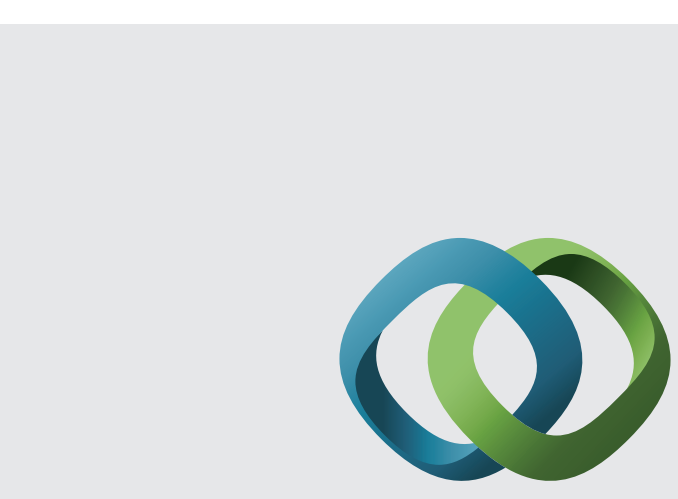

\section{Hindawi}

Submit your manuscripts at

http://www.hindawi.com
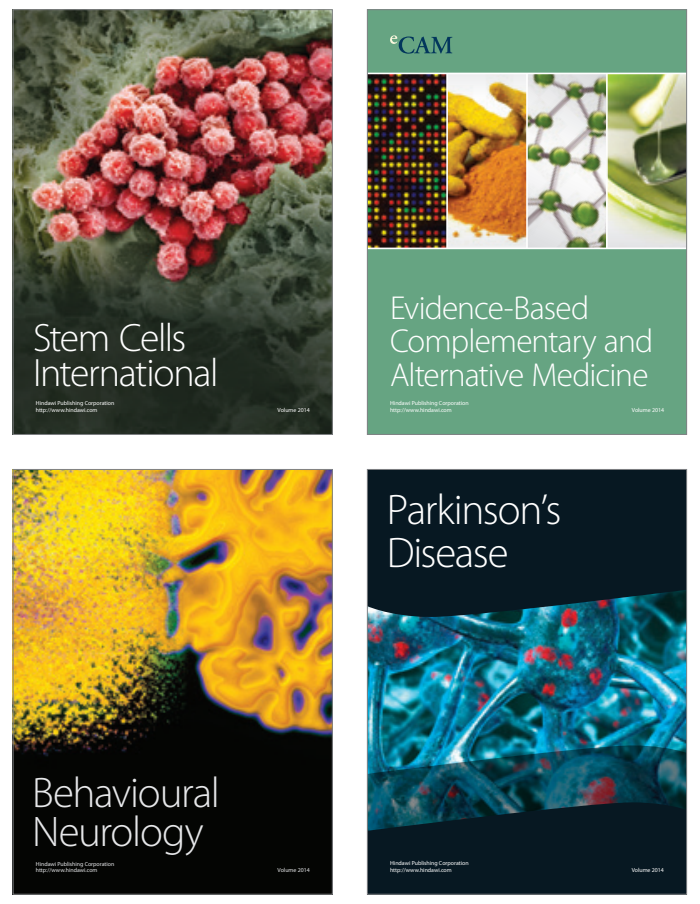
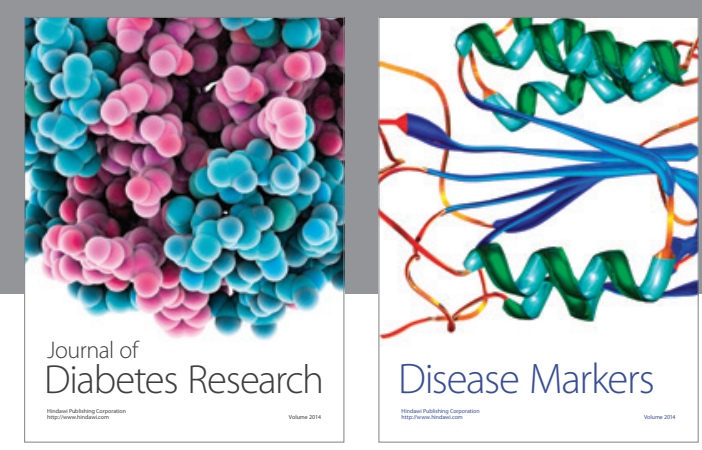

Disease Markers
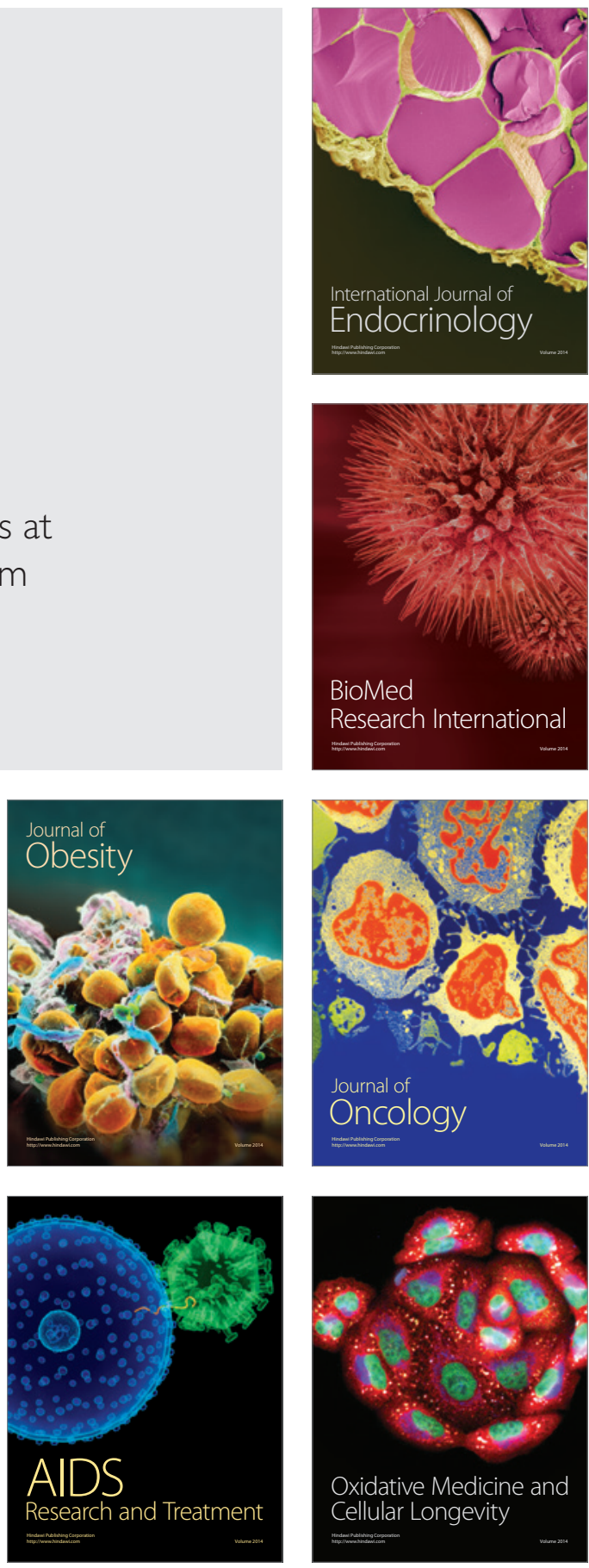